\title{
BOUNDARY PROBES: CONSIDERAÇÕES SOBRE INSTRUMENTOS INFLUENCIADORES DA NEGOCIAÇÃO COMERCIAL DE SERVIÇOS DE DESIGN
}

\author{
Melissa Merino Lesnovski \\ Universidade do Vale do Rio dos Sinos \\ melissa.lesnovski@gmail.com \\ Filipe Campelo Xavier da Costa \\ Universidade do Vale do Rio dos Sinos \\ fcampelo@unisinos.br
}

Resumo: As relações entre clientes e designers se iniciam na confecção da proposta comercial, um processo argumentativo, colaborativo e negocial cuja relevância não se exaure na assinatura do contrato de serviços, e sim continua como referência estrutural no processo de desenvolvimento dos serviços de design. O processo de confeç̧ão da proposta é marcado por tensões originárias tanto das posições relativas de poder entre designer e cliente quanto da própria subdeterminação do problema de design. 0 principal desafio proposto para este artigo é explorar a ideia do desenvolvimento de instrumentos que possam propiciar interação entre cliente e designer durante o processo negocial. Para tanto, as perspectivas de user studies, boundary objects e empatia em contextos negociais utilizadas neste artigo auxiliaram na condução de considerações preliminares para o desenvolvimento da empatia e assertividade em processos de negociação comercial. Os achados apontam diretrizes iniciais para a composição de artefatos provocadores da interação em contextos negociais contextos e considerações sobre futuras investigações sobre o tema.

Palavras-chave: codesign; boundary objects; sondas culturais; instrumentos de design estratégico; empatia

\begin{abstract}
Relationships between clients and designers start at the development of a commercial proposal, which is an argumentative, collaborative and negotiating process whose relevance does not end at the signing of the commercial contract, yet remains as a structural benchmark throughout the design services process. Proposal preparation is stressed by tensions that emerge both from the relative positions of power between designer and client and from the undetermined nature of the design problem itself. The main challenge for this article is exploring the idea of devising instruments that may foster interaction between client and designer during the negotiation process. In order to do so, the perspectives of user studies, boundary objects and empathy in negotiation contexts helped in conducting preliminary considerations for the development of
\end{abstract}


empathy and assertiveness in business negotiation processes. Findings lead us to preliminary guidelines for designing interaction-provoking artifacts in negotiation contexts and considerations about further research on the subject.

Keywords: codesign; boundary objects; cultural probes; strategic design instruments; empathy

\section{INTRODUÇÃO}

Um projeto de design começa muito antes do primeiro traço - mais precisamente, ele se inicia na etapa comercial, onde fornecedor e cliente propõem e negociam regras, limites, escopo e dotação orçamentária para o projeto. Essa etapa é finalizada por um acordo - ou proposta - comercial, que pode ser entendido como o design primeiro, ou embrionário, do projeto de design: um script onde são consolidados direcionamentos, atividades, esforços e limites para a prestação dos serviços.

O acordo comercial é baseado em uma série de informações obtidas pelo designer em um ciclo de levantamento de requisitos, que envolve tanto o cliente quanto o contexto do projeto. Esse ciclo é marcado pelo caráter reflexivo, onde as informações providas pelo cliente envolvem especialistas de diversas áreas (BUCCIARELLI, 2002), normalmente sem conhecimento específico em design, o que pode dificultar ao designer compreender, com precisão, as informações fornecidas e suas implicações (HAUG, 2015). É possível enxergar, nesse contexto, as tensões e contradições inerentes à subdeterminação do problema de design (DORST, CROSS, 2001), onde as definições de escopo são conjuntamente enquadradas e reenquadradas, pelos indivíduos envolvidos, de acordo com os limites em negociação.

Os atritos entre os diversos atores envolvidos no processo de design são recorrentes e discutidos por autores de domínios diversos como o codesign, design communications, engenharia e cultura de projeto, sendo a diversidade de modelos mentais uma das causas mais proeminentes das divergências. Autores como Kleinsmann e Valkenburg (2008) e Bucciarelli (1998) sugerem que a falta de conhecimento compartilhado nas equipes multidisciplinares seria oriunda da variabilidade de sentidos e artefatos atribuídos ao design. A dimensão social do design, portanto, emerge como um elemento significativo nos processos de projeto (CROSS, 1995) e torna-se instrumental para compreendermos o contexto em que uma proposta comercial de design é elaborada.

Se abordarmos o processo de composição de uma proposta comercial como um produto-serviço em si, podemos entender que tanto o designer quanto o cliente são usuários desse sistema de fluxos, interações e trocas de informações. A criação de um acordo comercial é um processo, em essência, colaborativo, no qual é urdida a infraestrutura de outro processo também colaborativo: o projeto de design em si. As duas instâncias - proposta comercial e projeto - são ameaçadas pela assimetria de poder, conflito de interesses e diferenças epistemológicas entre os indivíduos, evidenciados ou agravados pela falta de empatia entre eles.

Discutir sobre a falta de empatia em processos colaborativos do design envolve abordar a subdeterminação do problema de design e o impacto que esta acarreta no 
desenvolvimento de um projeto. Se o processo de abordagem do problema de design é reflexivo e dependente da interação entre atores de mundos sociais diferentes, sendo inócuas abordagens por soluções lineares, consideramos providencial a reflexão sobre a qualidade da relação entre os atores que elaboram, conjuntamente, o script desse processo na etapa comercial.

Se a colaboração entre fornecedor e cliente é proveitosa aos resultados da etapa comercial, indagamo-nos se seria possível projetar meios para o fomento da empatia entre os dois (ou mais) polos dessa negociação, potencializando a colaboração e o florescimento coletivo em direção a metas comuns desejadas. Entendemos que as explorações para responder a essa pergunta envolvem, inevitavelmente, reflexões sobre o significado da negociação, que envolve tanto as perspectivas de colaboração quanto de confronto e competição.

Este artigo pretende investigar, em caráter exploratório e preliminar, a pertinência e possíveis diretrizes para o uso de cultural probes, sob a perspectiva dos boundary objects, como elemento de fomento à empatia e articulação das diferenças entre participantes de um processo negocial comercial de design. Para tanto, buscouse referências nos temas da subdeterminação do problema de design, negociação, geração de empatia, boundary objects e sondas culturais.

As considerações finais, restritas às limitações inerentes à extensão deste artigo, alinham possíveis diretrizes para a elaboração de instrumentos capazes de suscitar a empatia, assertividade e colaboração entre atores de um processo negocial do design.

\section{REFERENCIAL TEÓRICO}

\subsection{A subdeterminação do problema de design}

O contexto de elaboração e negociação da proposta comercial de design não pode ser analisado separadamente dos referenciais teóricos do problema de design. Nessa fase inicial de tentativas de enquadramento do problema, também chamada de front-end ou, ainda, fuzzy front-end, os requisitos emergentes para a composição da proposta comercial são difusos, predominando a ambiguidade e natureza caótica, onde o entregável ainda não é discernível (SANDERS, STAPPERS, 2008).

Ao lançarmos mão dos referenciais de Dorst e Cross (2001), que apontam para a subdeterminação do problema de design, vemos que, em vez de uma solução direta e linear, há um processo reflexivo entre os espaços de problema e solução, que coevoluiriam ao longo do processo. A partir desse entendimento, há um desprendimento do paradigma de que o designer deve responder a um brief de design - em vez disso, o profissional define, junto ao cliente, o problema a ser enfrentado (BURNS et al., 2006). Da resposta ao brief à redefinição do próprio desafio, o papel do designer que tenta vender seus serviços envolve uma dinâmica colaborativa com o cliente e demais atores envolvidos no processo comercial. Esse novo papel implicaria em inspirar participação, habilitando possibilidades e relacionamentos entre os atores (BURNS et al., 2006). Torna-se visível o desafio que é proposto à comunidade de designers: ao assumirem a infraestruturação de um processo de design, o trade-off principal seria a abdicação da autoria exclusiva do projeto.

Esse processo menos focado na autoralidade do designer e mais aberto à participação e interferência do "outro" encontra eco em autores de outros domínios 
do design, como o os user studies e o codesign, abordados nos parágrafos a seguir. Ao debatermos o contexto de negociação comercial de serviços de design, portanto, entendemos que, ali também, a proposta comercial não é executada apenas pelo designer, e sim por meio da conversação reflexiva entre ele e os demais atores no projeto. Torna-se instrumental, pois, explorarmos o universo do "outro" nesse contexto.

\subsection{User studies}

Margolin (2007) considera todas as categorias de coisas materiais e imateriais como produtos: objetos, atividades, serviços e ambientes que preenchem o mundo. Assim sendo, quando falamos da relação entre um produto e um usuário, não estamos nos restringindo a produtos físicos, palpáveis e claramente individuados: podemos também nos referir a um processo, fluxos de informações e permissões. $O$ autor reforça a centralidade, no design, da relação entre os produtos, a projetação e os concerns dos usuários. Para ele, o produto não existiria no vácuo - sua significação só ocorreria em relação a um usuário. Existiria, portanto, uma proposta comercial, sua concepção e seu estudo sem levarmos em conta o usuário-cliente?

Os estudos do usuário surgem como uma tentativa de aproximar a visão do designer da realidade do usuário. Eles deveriam inspirar e informar o design, embora os designers não necessariamente se sintam inclinados a se deixarem inspirar por outras pessoas (MELICAN, 2004). Essa abertura do designer para perspectivas diferentes nos parece essencial para uma abordagem do design que seja tanto mais humana quanto adequada a cenários dinâmicos e complexos. A etnografia aplicada aproximaria o designer no ponto de vista do usuário (SANDERS, 2002) e facilitaria o processo colaborativo.

Reflexões sobre o design participativo e o codesign podem iluminar a análise de como um acordo comercial é construído: tecido entre duas ou mais partes, pode-se indagar se este não seria, por si só, um objeto coletivamente projetado. Sanders e Stappers (2008) vêem o codesign como uma instância específica da cocriação, onde a criatividade de designers e pessoas não treinadas em design seria envolvida em um processo de trabalho conjunto em design. A fronteira da legitimidade entre designers e não-designers foi referenciada por Burns et al. (2006), ao identificar grandes mudanças na primeira década do século XXI - onde as habilidades de design estariam sendo aplicadas e quem, realmente, estaria fazendo o design.

Podemos acrescer às tensões relativas ao trabalho colaborativo entre designer e cliente os atritos interentes a processos negociais, decorrentes dos significados que a negociação possui para um ou outro grupo de atores.

\subsection{Eu e o outro: a confiança dentro do contexto de negociação}

Em uma negociação, a confiança entre os atores é um fator preponderante para que existam acordos a favor do desenvolvimento coletivo dos participantes. Segundo Bussman e Muller (1992, apud. MARTINOVSKI et al, 2007), a negociação costuma ser definida como um processo comunicativo através do qual um grupo de pessoas ou agentes tenta chegar a um acordo mútuo aceitável em alguma questão. As habilidades de um indivíduo em uma negociação não se limitariam à capacidade de resolução de conflitos, mas também abrangeriam a proficiência comunicativa e gestão 
de emoções, sendo o envolvimento da empatia em processos negociais fomentador de abordagens mais colaborativas e menos focadas em conflitos (MARTINOVSKI et al, 2007).

Para Mnookin et al. (1996), o comportamento de negociação pode ser compreendido através de duas dimensões: a assertividade e a empatia. A assertividade compreenderia a capacidade de um indivíduo expressar e advogar por seus próprios interesses. A empatia envolveria a capacidade de demonstrar uma compreensão precisa e isenta de julgamentos das preocupações e perspectivas de outra pessoa. Essas duas dimensões não seriam mutuamente excludentes: assertividade e empatia, combinadas, trariam a melhor geração de valor ao processo.

Ao identificar as diversas combinações entre assertividade e empatia, Mnookin et al. (1996) reproduzem classificações, ou estilos, comuns à literatura sobre negociação. Podemos, nessas classificações, identificar três possíveis significados inerentes ao termo negociação: competição, acomodação e evitamento.

A empatia em processos negociais parece estar conectada a contextos de incerteza e abertura a desfechos desconhecidos, com possibilidade de mudança de objetivos, necessidades e comportamentos ao longo da comunicação (MARTINOVSKI et al, 2007). Nesse sentido, consideramos relevante relacionarmos os estudos da empatia às abordagens negociais da subdeterminação do problema de design.

Em uma negociação, a capacidade de demonstração de conhecimento do ponto de vista do outro, aliada à capacidade de expressar seu ponto de vista, podem propiciar vantagens relacionadas à perenidade do relacionamento e à criação e distribuição de valor (MNOOKIN et al., 1996). É providencial pontuar que, em uma relação entre designer e cliente, ao mesmo tempo em que ambos os lados possam carecer de empatia e assertividade em relação um ao outro, ambos podem colaborar para desenvolver ou suprir a qualidade faltante. Podemos nos conectar, portanto, ao pensamento de Burns et al. (2006), segundo o qual designers auxiliam seus clientes a definirem o problema a ser enfrentado. Esse auxílio à definição, que ocorre desde a etapa comercial, envolveria tanto a necessária empatia quanto o fomento à assertividade na definição de enquadramentos.

Enxergamos, assim, uma possível relação entre confiança, colaboração, empatia e assertividade dentro de contextos negociais, em especial aqueles que ocorrem em meio à incerteza e abertura ao desconhecido.

\subsection{Empatia e o fomento à colaboração no design}

Mattelmäki e Battarbee (2002) trazem reflexões sobre a empatia no design onde os indivíduos seriam vistos e compreendidos a partir de suas situações específicas vivenciadas e não como sujeitos desprovidos de sentimentos. A empatia no design possuiria, segundo elas, duas direções: em direção aos participantes, para criar um diálogo respeitoso e empático, e em direção aos designers para suportar a compreensão empática.

A empatia no design é necessária quando deslocamos nosso foco das questões práticas e racionais para as experiências pessoais e contextos privados (MATTELMÄKI, BATTARBEE, 2002). No campo do design participativo, observa-se grande quantidade de técnicas emergentes que exploram de forma ampla a vida do usuário, diferente de abordagens anteriores, focadas apenas na função (STAPPERS, SANDERS, 2003). Essa evolução constatada por Stappers e Sanders parece insinuar um direcionamento nos 
esforços da design research para o entendimento do outro - qualquer que seja a posição do outro dentro do ciclo de projeto e consumo.

Se a empatia no design, assim como nos referenciais de negociação, é tida como elemento essencial para o fomento à colaboração, como a design research poderia contribuir para estreitar o conhecimento do "outro" na relação entre cliente e designer?

\subsection{Sondas culturais e o entendimento do mundo do usuário}

Um dos instrumentos da design research que possibilitam um entendimento da realidade dos usuários são as sondas culturais, ou cultural probes, em inglês. Gaver et al. (1999) são os primeiros a descreverem a utilização de tais sondas como sistemas de artefatos e atividades projetados para provocar respostas inspiracionais em comunidades pesquisadas. As sondas eram parte de uma estratégia de exploração do design comercial de forma responsiva, visando o fomento de ideias inesperadas e a abertura de espaços de possibilidades (GAVER et al, 1999). Elas representavam uma maneira prática e criativa de aprender mais sobre o cotidiano das pessoas dentro de um contexto onde, devido a limitações de privacidade e tempo, não era possível conduzir observações participantes completas (LOI, 2007).

A própria palavra "sonda" sugere um dispositivo de gravação automática que é enviado a territórios desconhecidos onde pesquisadores humanos não podem ir - a partir de onde ele coleta amostras e as envia de volta aos pesquisadores (MATTELMÄKI, BATTARBEE, 2004). As sondas culturais geram dados inspiracionais, recolhem informações relevantes, amealham dados, ajudam a projetar e compreender o potencial para novas tecnologias (LOI, 2007).

$\mathrm{Na}$ forma, as sondas são pacotes de materiais especialmente planejados e executados, entregues aos usuários potenciais para documentar suas vidas privadas, contextos e experiências (MATTELMÄKI, BATTARBEE; 2002). Esses materiais não se diluem na realidade cotidiana dos informantes: o caráter das sondas culturais é deliberadamente estranho, lúdico e ambíguo, apresentando o mundo do participante como não familiar e forçando os designers a desafiarem conscientemente suas interpretações e pressuposições (GAVER et al., 1999).

Essa resposta aberta provocada pelas sondas é obtida mediante a provocação, a tentativa de mudança de percepções correntes envolvendo dimensões funcionais, estéticas, culturais e políticas (GAVER et al. 1999). As sondas, nesse sentido, parecem se alinhar com a perspectiva do reenquadramento sucessivo do problema de design (DORST, CROSS; 2001), pois não se baseiam em um pensamento cristalizado, e sim na exploração e levantamento de informações que subsidiem a reflexão.

As sondas culturais compartilham com a etnografia um interesse manifesto do pesquisador em entender mais sobre o outro. Ao contrário da etnografia, contudo, a utilização de sondas culturais não visa participar ou observar diretamente as práticas do outro, e sim analisar evidências deixadas após a interação do usuário com o material projetado da sonda. Embora haja diferenças entre as abordagens, tanto a etnografia quando as sondas culturais compartilham de um chão comum: são amplamente interpretativas, recorrem à empatia para entenderem como é ser o outro e jogam com a desfamiliarização como meio para obter subsídios. O projeto de uma sonda cultural, portanto, requer uma compreensão da área do estudo e a disposição 
para entender o informante - o primeiro passo para a construção da empatia (WRIGHT, MCCARTHY; 2008).

\subsection{Boundary Probes: sondas provocadoras da interação}

Se a geração da empatia parte da compreensão do outro (MATTELMÄKI, BATTARBEE, 2002) e essa compreensão pode ser fomentada pelo uso de sondas (GAVER, 1999), poderiam as sondas culturais, de acordo com Wright e McCarthy (2008), serem mais que um indutor de processo empático, e sim dialógico, articulando pontos de vista diferentes? Recorremos, para investigar essa questão, a Halpern et al. (2013), que abordam o uso de sondas culturais visando o fomento da colaboração entre grupos heterogêneos em projetos criativos, chamando-as de boundary probes (ou sondas fronteiriças, em tradução livre). Os autores trazem a perspectiva dos boundary objects para analisar propriedades das sondas que dêem partida à troca interdisciplinar e transfuncional no projeto.

A perspectiva dos boundary objects (objetos fronteiriços, em português) foi originalmente introduzida por Star e Griesemer (1989) para abordar a articulação de modelos mentais distintos, expondo divergências e construindo compatibilização e um contexto colaborativo. Segundo Star (2010), a cooperação entre atores envolve criar entendimentos comuns, assegurando a confiabilidade ao longo de diferentes domínios e reunindo informações que retêm sua integridade ao longo do tempo, espaço e contingências locais. Os boundary objects seriam artefatos (físicos ou conceituais) que articulariam indivíduos pertencentes a mundos sociais diferentes (STAR, GRIESEMER, 1989), ao mesmo tempo em que comunicariam e coordenariam as perspectivas desses diversos indivíduos (ARIAS, FISCHER, 2000).

Experiências projetadas, como as sondas, podem criar oportunidades para tanto o trabalho fronteiriço quanto para o estabelecimento de um chão comum, vital em contextos colaborativos. Embora essa experiência de colaboração seja projetada, ela não é controlada, e sim canalizada de forma intencional através de estruturas ou atividades particulares que proveriam embasamento para encorajar a interação e o rompimento das barreiras interpessoais, habilitando os indivíduos a reduzir as diferenças e construir a síntese como um grupo (HALPERN et al., 2013).

O estabelecimento de um denominador comum entre sujeitos de mundos sociais diferentes poderia ser obtido através do uso de um artefato, conceito ou outro tipo de objeto flexível o suficiente em significado ou apresentação e que suportasse uma variedade de interpretações presentes dentro de um grupo diverso (HALPERN et al., 2013). Os boundary objects, de acordo com Star e Griesemer (1989), são sujeitos a essas múltiplas interpretações sobrepostas, para que os atores possam enxergar além de suas próprias epistemologias para encontrar um cerne de entendimento compartilhado.

Halpern et al. (2013) propõem três diretrizes sobre a natureza das boundary probes: exogeneidade, estruturação e diversidade. Elas deveriam proporcionar um choque exógeno à estrutura social envolvida, empurrando-a além das suas conformações e práticas; prover uma estrutura reconhecida, que engedre o trabalho fronteiriço produtivo; e fomentar a diversidade, tirando partido da heterogeneidade da composição social. As boundary probes seriam, necessariamente, tarefas em grupo, convidativas à interpretação e construção de significado, tendo maior potencial para disparar discussões criativas. Sua utilização resultaria em compartilhar ideias, criar 
alianças, trocar informação e desenvolver o conhecimento compartilhado (HALPERN et al., 2013).

Uma outra perspectiva sobre as sondas culturais, proposta por Loi (2007) aprofunda a exploração do tema e, mesmo não assumindo diretamente o caráter fronteiriço das mesmas, se alinha à visão de Halpern et al. (2013) em relação ao caráter de instigação da colaboração entre os participantes. Loi (2007) propõe três derivados das sondas culturais, que promovem espaços múltiplos para usos de artefatos criativos, inspiracionais e provocativos: sondas reflexivas, sondas primitivas e gatilhos lúdicos.

As sondas reflexivas propostas por Loi (2007) criam as condições para a prática reflexiva através de artefatos criativos inspiradores e ambíguos. Tais sondas deveriam ser desenvolvidas de acordo com cada contexto onde seriam aplicadas e teriam grande potencial em contextos corporativos, por seu caráter de consciência e reflexividade. Elas também facilitariam outras atividades de cunho etnográfico, testes em usuários e codesign. Loi (2007) também propõe sondas "primitivas", que seriam construídas pelos próprios participantes a partir de insumos providos pelos designers: uma forma embrionária e generativa de sonda que provoca, programa e habilita o participante a projetar uma sonda e aplicá-la em si próprio ou nos outros. Por último, Loi (2007) também propõe gatilhos lúdicos, que reativariam a possibilidade de as pessoas brincarem, cogitarem e aprenderem, descobrindo ou redescobrindo prazeres e benefícios dessas experiências. O engajamento reflexivo, a comunicação frutífera e colaboração melhorada são os resultados principais da prática, focando na criação de diálogos, agindo como dispositivos de comunicação e ativando modos receptivos de engajamento.

Podemos imaginar uma possível conexão entre o caráter articulador do gatilho lúdico de Loi (2007) às boundary probes propostas por Halpern et al. (2013), no sentido de que ambas as abordagens provocam os usuários a partir de estímulos situados fora de suas fronteiras, estimulando os indivíduos a compartilharem experiências e construírem pontes entre seus universos - tanto em uso direto (HALPERN et al. 2013) quanto exponencial (LOI, 2007).

\section{DISCUSSÃO}

A partir das referências analisadas e à luz do contexto estudado, propomos cinco eixos de discussão sobre a pertinência da utilização de sondas culturais, na perspectiva dos boundary objects, dentro de contextos negociais de projetos de design para fomento da empatia e assertividade necessárias à interação geradora de valor.

\subsection{O usuário-participante como agente do enquadramento do problema de design}

Se os designers estão apenas começando a trabalhar na definição de problemas (BURNS et al. 2006), lançamos o questionamento: não seria o primeiro grande problema a ser abordado a investigação sobre o usuário-participante inicial de um projeto de design, que seria o cliente? Melican (2004) revela uma riqueza de possibilidades e acepções para a palavra "usuário" que é restringida em nossas abordagens mais limitadas do termo. Assim, um usuário não seria apenas o que utiliza uma solução criada por outrem, mas também aquele que participa, cria, provoca, interage, interfere. 
Essa visão multiperspectivada do usuário pode validar a decisão da utilização da sonda, tanto no caráter original (enquanto sonda cultural) quanto no fronteiriço (como boundary probe), para investigar o processo negocial do design e dele extrair fragmentos de inspiração. Torna-se interessante, para o pesquisador interessado em compreender o que vê e o que sente cada ator de um processo negocial, obter informações de campo que não seriam facilmente capturadas através de entrevistas ou observação participante. Da mesma forma, valida-se a pertinência da intenção de nos utilizarmos da sonda para suscitarmos empatia e fomentarmos a assertividade entre os participantes envolvidos: além de benefícios inerentes aos materiais a serem coletados na própria pesquisa, a empatia e a assertividade poderiam ser também proveitosas para o melhor desenvolvimento do próprio processo negocial.

\subsection{Empatia e assertividade em múltiplas direções}

Nas referências teóricas deste artigo, observamos que a empatia abordada no contexto das boundary probes assume dois vetores: do pesquisador-designer da sonda para com os usuários-participantes da mesma e entre os usuários-participantes (MATTELMÄKI, BATTARBEE, 2002). O projeto de uma sonda cultural, iniciado por um profundo conhecimento do campo (WRIGHT, MCCARTHY, 2008), deve também contemplar uma estruturação de elementos que sejam generativos de dados ricos a serem extraídos de campo e que facilitem a interação e, principalmente, o entendimento mútuo dos participantes envolvidos. Objetos e atividades que incentivem os usuários-participantes a se colocarem no lugar um do outro, compartilhando suas referências, anseios e visões de mundo, poderão tanto prover informações valiosas ao pesquisador quanto preparar os participantes para atividades sucessivas dentro do mesmo contexto de sondagem ou mesmo para a negociação em si. Ao falar sobre si, o participante tanto fomenta a empatia no outro quanto desenvolve sua própria assertividade, adquirindo confiança para alinhar suas necessidades e desejos.

Duas modalidades de sonda propostas por Loi (2007) parecem ser referenciais na geração multidirecional de empatia: as sondas reflexivas que, por meio de inputs criativos, levam o participante a refletir sobre a própria prática; e as sondas primitivas que, por seu caráter generativo, permitiriam aos participantes criarem sondas para investigarem uns aos outros. Nesse último quesito, a composição das sondas por um participante poderia ser tão ou mais interessante para a pesquisa quanto os dados gerados por ela, pois traria, potencialmente, evidências sobre que tipo de estranhamento ou fascinação o outro suscita nele.

\subsection{O lúdico como indutor do interesse e da participação}

A utilização de gatilhos lúdicos como instigadores da interação entre os participantes pode abrir possibilidades de brincadeira, reflexão e aprendizado conjunto (LOI, 2007).

Inicialmente, neste exercício de exploração, indagamo-nos se a diretriz de ludicidade inspirada pelos gatilhos lúdicos não seria, até certo ponto, contraproducente se utilizada isoladamente na geração de empatia em pares negociais sem rapport mútuo. O contexto, nesse caso, poderia ser influenciador do ajuste ou desajuste da sonda: dentro de uma negociação, o significado da gravidade dos interesses ali em jogo não deve ser desconsiderado. 
Por outro lado, Loi (2007) propõe os gatilhos lúdicos precisamente por seu desajuste da realidade, estabelecendo uma conexão entre os participantes que, de outra forma, seria dificultada pelas barreiras oriundas dos modelos mentais envolvidos. Nesse sentido, mesmo Loi não citando expressamente o caráter fronteiriço das sondas, este aparece de forma clara, quando esta defende a criação dos gatilhos lúdicos como elementos articuladores e incitadores da colaboração, vinculando-os a iniciativas de codesign.

\subsection{Desfamiliarização: o papel do diferente, estranho, oblíquo e ambíguo na construção de pontes entre mundos diferentes}

Fator recorrente na análise de diversos autores sobre sondas culturais, a desfamiliarização aparece como elemento essencial a ser levado em consideração no projeto de uma sonda (GAVER et al., 1999; HALPERN et al., 2013; LOI, 2007), tanto na sua acepção original, como sonda cultural, quanto na abordagem de boundary probe. O oblíquo, lúdico e estranho presente nos artefatos produzidos provoca os participantes com estímulos deliberadamente desajustados de sua realidade, afastando-os de sua zona de conforto e pressuposições automáticas. Ressaltamos, a partir da leitura dos autores supracitados, que a desfamiliarização também pode trabalhar a favor do próprio designer, instigando-o a pensar de forma diferente das suas usuais pressuposições.

\subsection{Estruturação: componentes, dinâmicas e camadas de interação}

Se as sondas culturais devem ser estruturadas de forma a permitir aos usuários documentar suas vidas privadas, contextos e experiências (MATTELMÄKI, BATTARBEE, 2002), quando são utilizadas como boundary probes, também podem contemplar a construção de pontes, fomento à empatia e instigação ao diálogo entre os participantes. Nesse sentido, ferramentas, rotinas, protocolos e ambientes colaborativos poderiam prover estruturação para empurrar além das barreiras interpessoais comuns e encorajar a interação (HALPERN et al, 2013).

O projeto de uma boundary probe deve considerar a imponderabilidade inerente à aplicação da mesma em sujeitos humanos: a estruturação é realizada de forma a suportar os objetivos pretendidos, canalizando intencionalmente as respostas através de estruturas ou atividades particulares (HALPERN et al, 2013).

Diferentes visões e intenções sobre uma sonda podem levar a diferentes estruturações da mesma, como no caso das sondas primitivas de Loi (2007), onde o projeto da sonda envolve a preparação de uma infraestrutura sobre a qual novas sondas seriam geradas pelos indivíduos participantes. A abertura do pesquisador aos resultados, nesse caso, parece essencial: no momento em que se abre ao próprio usuário-participante a possibilidade de elaborar sua própria sonda, aumentamos o grau de entropia e complexidade do contexto. O resultado, apesar de menos suscetível a análises cartesianas, poderá ser útil como fonte de insights e inspirações, além de suscitar conversações produtivas à colaboração.

\section{CONSIDERAÇÕES FINAIS}

A partir das referências estudadas e das articulações urdidas, enxerga-se a possibilidade da utilização de sondas culturais, na perspectiva dos boundary objects, para investigar e suscitar empatia e assertividade em contextos negociais do design. 
Em que pese o caráter essencialmente aberto e exploratório da abordagem das sondas culturais, identificou-se linhas comuns e complementares entre os autores abordados, possibilitando a elaboração de um conjunto de reflexões sobre possíveis diretrizes (ou itens de atenção) para a construção de dinâmicas e sistemas de boundary probes dentro do contexto negocial do design. A curiosidade e abertura em relação ao outro parece permear todos os esforços aqui pesquisados, sendo as diferenças de procedimentos variações mais ou menos adaptáveis a cada contexto a ser explorado e a cada conjunto de objetivos inerentes ao processo de projetação.

Essa curiosidade parece estar alinhada à subdeterminação do problema de design: a partir do momento em que se assume que não há soluções definitivas, mas enquadramentos sucessivos e móveis do problema em uma realidade complexa, a busca constante de informações sobre o elemento humano envolvido ora como agente, ora como utilizador dos produtos e processos de design torna-se essencial para alimentar e retroalimentar o processo com inspiração, limites e referências.

Entendemos que, dadas as limitações inerentes ao tamanho deste artigo, ao seu caráter exploratório e à brevidade da pesquisa, sua contribuição é modesta frente ao rico cenário de possibilidades de investigação. Futuros estudos poderão aprofundar o escopo das discussões, analisando aplicações das boundary probes em contextos negociais assim como empreendendo formatos complementares de investigação que enriqueçam o panorama geral de informações obtidas.

Caso se deseje, futuramente, partir do contexto exploratório deste artigo e enveredar por investigações que almejem aferir a extensão do impacto da utilização das boundary probes em contextos negociais, antevemos desafios metodológicos futuros que deverão ser considerados pelos pesquisadores. Um deles é a consideração sobre se essa aferição será realizada em grupos negociais reais ou simulados. Levandose em conta que o conflito de interesses é uma das realidades basais sobre as quais nossos esforços de geração de empatia e assertividade presentes neste artigo são perfilados, uma situação em que os conflitos de interesse não sejam sentidos pelos participantes poderá carecer de validade científica em seus resultados.

\section{REFERÊNCIAS}

ARIAS, Ernesto G.; FISCHER, Gerhard. Boundary objects: their role in articulating the task at hand and making information relevant to it. 2000.

BUCCIARELLI, Louis $L$. An ethnographic perspective on engineering design. Design Studies, v. 9, n. 3, p. 159-168, 1988.

BUCCIARELLI, Louis L. Between thought and object in engineering design. Design Studies, v. 23, n. 3, p. 219-231, 2002.

BURNS, Colin et al. RED paper 02: Transformation design. London: Design Council, 2006.

BUSSMANN, Stefan; MULLER, Jorg. A negotiation framework for co-operating agents. Proceedings of CKBS-SIG, p. 1-17, 1992.

DORST, Kees; CROSS, Nigel. Creativity in the design process: co-evolution of problemsolution. Design Studies, v. 22, n. 5, p. 425-437, 2001. 
GAVER, Bill; DUNNE, Tony; PACENTI, Elena. Design: cultural probes. Interactions, v. 6, n. 1, p. 21-29, 1999.

HALPERN, Megan K. et al. Designing collaboration: comparing cases exploring cultural probes as boundary-negotiating objects. In: Proceedings of the 2013 conference on Computer supported cooperative work. ACM, 2013. p. 1093-1102.

HAUG, Anders. Emergence patterns for client design requirements. Design Studies, v. 39, p. 48-69, 2015.

KLEINSMANN, Maaike; VALKENBURG, Rianne. Barriers and enablers for creating shared understanding in co-design projects. Design Studies, v. 29, n. 4, p. 369-386, 2008.

LOI, Daria. Reflective probes, primitive probes and playful triggers. Working paper, EPIC07: Ethnographic Praxis in Industry Conference, Keystone, Colo. 2007.

MARGOLIN, Victor. Getting to know the user. Design Studies, v. 18, n. 3, p. 227-236, 1997.

MARTINOVSKI, Bilyana; TRAUM, David; MARSELLA, Stacy. Rejection of empathy in negotiation. Group Decision and Negotiation, v. 16, n. 1, p. 61-76, 2007.

MATTELMÄKI, Tuuli; BATTARBEE, Katja. Empathy probes. In: PDC. 2002. p. 266-271.

MELICAN, Jay. User studies: Finding a place in design practice and education. Visible Language, v. 38, n. 2, p. 168, 2004.

MNOOKIN, Robert H.; PEPPET, Scott R.; TULUMELLO, Andrew S. The tension between empathy and assertiveness. Negotiation Journal, v. 12, n. 3, p. 217-230, 1996.

SANDERS, Elizabeth. Special section: ethnography in NPD research. How 'applied ethnography'can improve your NPD research process. Visions Magazine. 2002.

SANDERS, Elizabeth B.-N.; STAPPERS, Pieter Jan. Co-creation and the new landscapes of design. Co-design, v. 4, n. 1, p. 5-18, 2008.

STAPPERS, Pieter Jan; SANDERS, Elizabeth BN. Generative tools for context mapping: tuning the tools. In: Design and Emotion. 2003.

STAR, Susan Leigh. This is not a boundary object: Reflections on the origin of a concept. Science, Technology \& Human Values, v. 35, n. 5, p. 601-617, 2010.

STAR, Susan Leigh; GRIESEMER, James R. Institutional ecology,translations' and boundary objects: Amateurs and professionals in Berkeley's Museum of Vertebrate Zoology, 1907-39. Social studies of science, v. 19, n. 3, p. 387-420, 1989.

WRIGHT, Peter; MCCARTHY, John. Empathy and experience in $\mathrm{HCl}$. In:Proceedings of the SIGCHI Conference on Human Factors in Computing Systems. ACM, 2008. p. 637646. 